\title{
Avaliação nutricional da silagem de grãos úmidos de sorgo de alto ou de baixo conteúdo de taninos para leitões na fase de creche
}

\author{
Valquiria Mayumi Ishida Patricio, Antonio Claudio Furlan², Ivan Moreira², Elias Nunes \\ Martins $^{2}$, Clóves Cabreira Jobim ${ }^{2}$, Ciniro Costa ${ }^{3}$
}

\author{
${ }^{1}$ Programa de Pós-Graduação em Zootecnia. \\ 2 DZO-PPZ-UEM-Maringá-PR-Av. Colombo, 5790, CEP: 87020-900. \\ 3 UNESP-Botucatu-SP.
}

RESUMO - Foram realizados dois experimentos com o objetivo de avaliar a utilização da silagem de grãos úmidos de sorgo (SGUS) de alto ou baixo conteúdo de tanino na alimentação de leitões na fase de creche. No ensaio de digestibilidade, foram utilizados

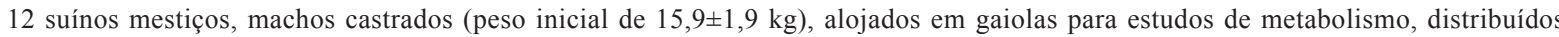
em um delineamento experimental inteiramente casualizado, com quatro repetições, em que a unidade experimental foi constituída por um leitão. O método utilizado foi o de coleta total de fezes e urina. Os valores de MS, proteína, amido, MO e energia digestíveis e os de EM, na matéria natural $(68,75 \%$ de MS), foram, respectivamente, 43,94; 5,45;46,67;63,46\%; 2.700 e $2.674 \mathrm{kcal} / \mathrm{kg}$ para a SGUS de alto teor de tanino e 40,72; 5,92; 44,08; 63,75\%; 2.641 e $2.608 \mathrm{kcal} / \mathrm{kg}$, para SGUS de baixo conteúdo de tanino. O segundo experimento foi conduzido para avaliar o desempenho de leitões e a viabilidade econômica da utilização de rações com diferentes níveis de substituição do milho seco por SGUS de alto ou baixo teor de tanino. Foram utilizados 56 suínos mestiços $(14,7 \pm 1,9$ e 29,2 $\pm 3,0 \mathrm{~kg}$ de pesos inicial e final) distribuídos em um delineamento inteiramente casualizado, com quatro repetições e dois leitões por unidade experimental. Os tratamentos consistiram de uma ração à base de milho e farelo de soja e de outras seis com 33, 66 e 100\% de substituição do milho seco por SGUS de alto ou baixo conteúdo de taninos, com base nos valores de energia digestível (ED) desses ingredientes. Não foram observadas diferenças no desempenho dos animais entre os tratamentos, entretanto, houve aumento linear no consumo diário de ração para a SGUS de baixo teor de tanino e redução linear para o custo da ração por quilograma de peso vivo ganho para a SGUS de alto teor de tanino.

Palavras-chave: desempenho, digestibilidade, suínos, valores energéticos

\section{Nutritional evaluation of high moisture sorghum silage grain of high or low tannin contents for nursery piglets}

\begin{abstract}
Two trials were carried out to evaluate the feeding of high moisture sorghum silage (HMSS) of high or low tannin contents for piglets. In the digestibility trial, twelve crossbred, castrated males, averaging initial body weight of $15.9 \pm 1.9 \mathrm{~kg}$ were allotted to metabolism cages, as a completely randomized design, with four experimental units and one piglet per cage. The total feces and urine collection method was used. The values of digestible DM, digestible protein, digestible starch, digestible OM, digestible energy and ME of HMSS of high tannin were, respectively, of 43.94, 5.45, 46.67, 63.46\%, 2,700, and 2,674 kcal $/ \mathrm{kg}$ and of HMSS of low tannin were of $40.72,5.92,44.08,63.75 \%, 2,641$, and $2,608 \mathrm{kcal} / \mathrm{kg}$ respectively, as-fed basis $(68.75 \% \mathrm{DM})$. The second trial was carried out to evaluate piglet performance and economic viability of diets with different dry yellow corn replacement levels

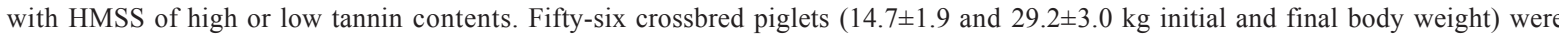
allotted to four treatments as a completely randomized design, with four experimental units of two piglets. The treatments consisted of a basal corn-soybean meal based diet and six diets of dry corn replacement with 33, 66, and 100\% of HMSS of high or low tannin contents based on the digestible energy contents of these feedstuffs. No treatment effect on piglet performance was observed, however, there was linear increasing effect on daily feed intake for HMSS of low tannin and linear decreasing effect for diet cost per kilogram of weight gain for HMSS of high tannin.
\end{abstract}

Key Words: digestibility, energy values, performance, swine

\section{Introdução}

Como o milho é o principal componente das rações para suínos, seu custo tem sido um dos grandes problemas para os suinocultores. A ocorrência de produções limitadas, de políticas reguladoras de estoque, entre outros fatores, em determinados anos tem levado diversos produtores à tentativa de utilização de ingredientes alternativos na alimentação animal. 
O uso de grãos úmidos, principalmente de milho, na forma de silagem em rações para suínos tem sido uma alternativa para a produção de grãos na propriedade, tendo em vista suas vantagens em relação ao milho seco: ausência de taxas e impostos sobre o produto, de perdas econômicas com transporte, frete e desconto sobre a umidade; baixo custo de armazenamento; antecipação do período de colheita; e menores perdas por ataques de roedores e insetos (Nummer, 2001).

A utilização de silagem de grãos úmidos de milho na alimentação animal foi estudada inicialmente nos países da Europa, nos Estados Unidos e no Canadá. No Brasil, essa prática foi introduzida em 1981, na região de Castro - PR, em criações de suínos e, posteriormente, nas de bovinos de leite e de corte (Kramer \& Voorsluys, 1991).

A substituição do milho seco por grão de sorgo em forma de silagem na alimentação animal tem sido mais uma opção para a redução dos custos das rações. O sorgo possui ótima adaptabilidade aos diversos tipos de solos e climas do Brasil. Pode ser cultivado em áreas com menor disponibilidade de água e, por sua maior resistência hídrica, possibilita mais opções de plantio que o milho (Nunes et al., 2001). Além disso, em regiões semi-áridas e tropicais, a cultura do sorgo apresenta melhor rendimento de nutrientes por unidade de área (Rostagno, 1986).

Embora os resultados das análises químicas proximais dos grãos de milho e de sorgo sejam semelhantes, o valor nutritivo do sorgo corresponde de 90 a $95 \%$ ao do milho quando utilizado em rações para suínos nas fases de crescimento e terminação (Gontijo et al., 1976).

O sorgo apresenta nível de $\mathrm{PB}$ um pouco superior ao do milho (Rostagno et al., 2000) e pode ser considerado equivalente ao milho em minerais e vitaminas. É deficiente em gordura e pobre em substâncias pigmentantes, podendo conter, dependendo da variedade, altos níveis de tanino.

Os taninos são compostos fenólicos de alto peso molecular, que, além de comprometer a palatabilidade, diminuem a digestibilidade, especialmente de proteína e amido (Makkar, 1988), e os valores energéticos do alimento (Lizardo et al., 1995).

De acordo com Cousins et al. (1981), o sorgo de baixo teor de tanino apresenta digestibilidade dos nutrientes semelhante à do milho em suínos na fase de crescimento. Lizardo et al. (1995), no entanto, afirmam que o sorgo de baixo conteúdo de tanino pode ser utilizado em quantidades similares às do milho em dietas para leitões na fase inicial, porém, há restrições no uso do sorgo de alto teor de tanino, haja vista seus menores teores de EM (Halley et al., 1986).
A incubação anaeróbica do sorgo de alta umidade tem sido utilizada para minimizar o tanino quimicamente detectável (Teeter et al., 1986) e melhorar o desempenho animal (Mitaru et al., 1984a), pois, segundo Van Soest (1994), os taninos podem ser hidrolisados para açúcares em meio ácido e, portanto, pode-se levantar a hipótese de que a acidez da silagem exerce importante papel na digestão de grãos de sorgo de alto teor de tanino.

Lopes et al. (2002) observaram que silagens de grãos úmidos de sorgo de baixo conteúdo de tanino proporcionaram melhor desempenho de leitões na fase de creche e que a silagem de grãos úmidos de sorgo de alto conteúdo de tanino apresentou valor nutricional semelhante ao do milho seco.

Considerando que a produção de sorgo tem aumentado significativamente nas propriedades agrícolas brasileiras e que a literatura nacional oferece poucas informações sobre a utilização da silagem de grãos na alimentação animal, avaliou-se, nutricionalmente, por meio de ensaio de digestibilidade e experimento de desempenho, o uso das silagens de grãos úmidos de sorgo de alto e baixo conteúdo de tanino em substituição ao milho seco em rações para leitões em fase de creche.

\section{Material e Métodos}

Foram realizados dois experimentos no setor de suinocultura da Fazenda Experimental de Iguatemi (FEI), pertencente ao Centro de Ciências Agrárias da Universidade Estadual de Maringá (CCA/UEM).

No ensaio de digestibilidade, foram utilizados 12 suínos mestiços (Landrace x Large-White $x$ Duroc), machos castrados, com 15,9 $\pm 1,9 \mathrm{~kg}$ de peso inicial. Os animais foram alojados em gaiolas para estudos de metabolismo semelhantes às descritas por Pekas (1968). O período experimental incluiu cinco dias de adaptação às gaiolas e às rações experimentais e cinco dias de coletas de fezes e urina. $\mathrm{O}$ delineamento experimental foi inteiramente ao acaso, com quatro repetições, em que a unidade experimental foi constituída por um suíno.

A ração-referência foi formulada de acordo com a composição química e os valores energéticos dos ingredientes, segundo tabelas da EMBRAPA (1991). Os alimentos avaliados foram as silagens de grãos úmidos de sorgo de alto e de baixo teor de tanino (alimentos-teste), substituindo, com base na MS, 30\% da ração-referência (RR), resultando em duas rações-teste (RT) que foram pesadas e misturadas diariamente.

A SGUS de alto conteúdo de tanino foi confeccionada em maio de 2002 e ensilada em tambores de polietileno com capacidade para 200 L. Nessa ocasião, os grãos apresentavam 
$31,25 \%$ de umidade. A variedade de sorgo de baixo conteúdo de tanino foi cultivada em novembro de 2001. A colheita foi realizada por colhedeira mecânica, no momento em que os grãos apresentavam-se farináceos e com teor de umidade de $34,10 \%$. Os grãos foram triturados em moinho do tipo martelo com peneira de $6 \mathrm{~mm}$ e ensilados em manilhas de concreto com capacidade para $1.000 \mathrm{~L}$.

As rações foram fornecidas diariamente em porções iguais, às 8 e 14h. A quantidade total diária foi estabelecida de acordo com o menor consumo por peso metabólico $\left(\mathrm{kg}^{0,75}\right)$ observado na fase de adaptação para cada unidade experimental.

Após cada refeição, foi fornecida água no comedouro, em proporção calculada de $3,0 \mathrm{~mL} / \mathrm{g}$ de ração para cada unidade experimental para evitar excesso no consumo de água. Adotou-se o método de coleta total de fezes, com a adição de $2 \%$ de óxido de ferro $\left(\mathrm{Fe}_{2} \mathrm{O}_{3}\right)$ às rações como marcador do início e do fim da coleta de fezes.

As fezes totais produzidas foram coletadas uma vez ao dia, acumuladas em sacos plásticos e armazenadas em congelador a $-18^{\circ} \mathrm{C}$. Posteriormente, foram homogeneizadas e uma amostra de $20 \%$ foi retirada, seca em estufa de ventilação forçada $\left(55^{\circ} \mathrm{C}\right)$ e moída para determinação dos teores de MS, amido, MO, PB e EB. A urina foi coletada diariamente em baldes plásticos contendo $20 \mathrm{~mL}$ de $\mathrm{HCl} 1: 1$ e uma alíquota de $20 \%$ foi acumulada diariamente e congelada a $-18^{\circ} \mathrm{C}$. Posteriormente, essas alíquotas foram homogeneizadas e amostradas para determinação dos teores de EB. Os teores de EB das rações, das silagens, das fezes e da urina foram determinados por meio de calorímetro adiabático (Parr Instrument Co., 1984).

As análises dos alimentos, das fezes e da urina foram realizadas segundo procedimentos descritos por Silva (1990). Foram determinados os teores de amido dos alimentos e das fezes de acordo com o método enzimático proposto por Poore et al. (1989), adaptado por Pereira \& Rossi (1995). Os valores do $\mathrm{pH}$ das SGUS de alto e de baixo teor de tanino foram determinados pelo método utilizado por Phillip \& Fellner (1992) e a granulometria segundo metodologia descrita por Zanotto \& Bellaver (1996).

Os teores de tanino dos grãos de sorgo secos e dos grãos úmidos antes da ensilagem e nas silagens, depois do processo fermentativo, foram determinados pelo Método Azul da Prússia, descrito por Magalhães et al. (2000). Foram realizadas avaliações da estabilidade aeróbica das silagens, tomando-se, simultaneamente, a temperatura ambiente (Kung Jr., 2001) e a temperatura das silagens no momento e 1, 2, 3, 6, 7, 8, 9 e 10 horas após a abertura dos silos.

Os coeficientes de digestibilidade aparente da MS (CDMS), da proteína bruta (CDPB), do amido (CDAM), da
$\mathrm{MO}(\mathrm{CDMO})$, da EB(CDEB) e o coeficiente de metabolização da EB (CMEB) dos alimentos-teste foram determinados pelo método de coleta total de fezes e urina, conforme Moreira et al. (1994).

Os teores de nutrientes digestíveis dos alimentos foram calculados utilizando-se a fórmula de Matterson et al. (1965).

Os coeficientes de digestibilidade dos nutrientes das duas variedades de sorgo ensiladas foram analisados de acordo com o modelo estatístico:

$$
\mathrm{Y}_{i j}=\mathrm{u}+\mathrm{T}_{i}+\mathrm{e}_{i j}
$$

em que: $\mathrm{Y}_{i j}=$ coeficientes de digestibilidade aparente de MS, MO, PB, amido e EB de cada indivíduo $j$ recebendo o sorgo $i ; \mathrm{u}=$ constante geral; $\mathrm{T}_{i}=$ efeito da variedade de sorgo ensilado $i$, sendo $i=1 ; 2$ ( $1=$ silagem de grãos úmidos de sorgo de alto teor de tanino e 2 = silagem de grãos úmidos de sorgo de baixo teor de tanino); $\mathrm{e}_{i j}=$ erro aleatório associado a cada observação $\mathrm{Y}_{i j}$.

As médias dos coeficientes de digestibilidade foram comparadas pelo teste $\mathrm{F}(\mathrm{P}<0,05)$.

No experimento de desempenho, foram utilizados 56 leitões (28 machos e 28 fêmeas) mestiços Landrace, LargeWhite e Duroc (45 dias de idade e 14,7 $\pm 1,9 \mathrm{~kg}$ de PV inicial), distribuídos em sete tratamentos, que consistiram de duas repetições casualisadas dentro de cada sexo e dois leitões por unidade experimental.

As pesagens dos animais foram realizadas no início e ao final do período experimental (21 dias), quando apresentaram 29,2 $\pm 3,0 \mathrm{~kg}$ de peso médio final (fase de creche).

Os tratamentos experimentais (Tabela 1) consistiram de uma ração-referência à base de milho seco e de outras seis nas quais o milho seco foi substituído pelas silagens de grãos úmidos de sorgo (SGUS) de alto e de baixo conteúdo de tanino (com base nos valores energéticos convertidos para $87,45 \%$ de MS em níveis de 33, 66 e 100\%), formuladas para atender às exigências nutricionais descritas por Rostagno et al. (2000) para leitões de médio potencial genético, na respectiva faixa etária. As rações foram isoenergéticas, isocalóricas, isocálcicas, isofosfóricas e isoaminoacídicas para lisina e metionina + cistina.

As composições de aminoácidos das SGUS foram recalculadas de acordo com os teores de $6,33 \%$ de $\mathrm{PB}$, para SGUS de alto conteúdo de tanino, e de $6,83 \%$, para a SGUS de baixo conteúdo de tanino (determinados no LANA DZO/UEM), e com a concentração de aminoácidos do sorgo apresentada nas tabelas da EMBRAPA (1991).

Os ingredientes das rações, exceto as SGUS de alto e baixo teor de tanino, foram previamente misturados. As SGUS de alto e baixo conteúdo de tanino foram incorporadas diariamente às respectivas rações nos níveis de 33, 66 e $100 \%$ de substituição ao milho seco. 
Tabela 1 - Composição dos ingredientes das rações experimentais

Table 1 - Ingredient composition of the experimental diets

\begin{tabular}{|c|c|c|c|c|c|c|c|}
\hline \multirow[t]{3}{*}{$\begin{array}{l}\text { Ingrediente } \\
\text { Ingredient }\end{array}$} & \multirow[t]{3}{*}{$\begin{array}{l}\text { Ração-referência } \\
\text { Control }\end{array}$} & \multicolumn{6}{|c|}{$\begin{array}{l}\text { Nível de substituição do milho seco comum por SGUS (\%) } \\
\text { Level of dry corn replacement with HMSS (\%) }\end{array}$} \\
\hline & & \multicolumn{3}{|c|}{$\begin{array}{l}\text { SGUS alto tanino } \\
\text { High tannin HMSS }\end{array}$} & \multicolumn{3}{|c|}{$\begin{array}{l}\text { SGUS baixo tanino } \\
\text { Low tannin HMSS }\end{array}$} \\
\hline & & 33 & 66 & 100 & 33 & 66 & 100 \\
\hline Milho seco grão ${ }^{1}$ (Dry corn grain) & 61,516 & 41,000 & 20,500 & - & 41,000 & 20,500 & - \\
\hline SGUS $^{1}(H M S S)$ & - & 20,840 & 41,680 & 62,520 & 20,350 & 40,690 & 61,040 \\
\hline Açúcar (Sugar) & 3,000 & 3,000 & 3,000 & 3,000 & 3,000 & 3,000 & 3,000 \\
\hline Fosfato bicálcico (Dicalcium phosphate) & 1,725 & 1,740 & 1,756 & 1,771 & 1,760 & 1,790 & 1,820 \\
\hline Calcário (Limestone) & 0,802 & 0,798 & 0,794 & 0,790 & 0,766 & 0,735 & 0,705 \\
\hline Sal comum (Salt) & 0,400 & 0,400 & 0,400 & 0,400 & 0,400 & 0,400 & 0,400 \\
\hline Tylan S-100 & 0,100 & 0,100 & 0,100 & 0,100 & 0,100 & 0,100 & 0,100 \\
\hline DL-metionina (DL-methionine) & 0,001 & 0,013 & 0,024 & 0,035 & - & - & - \\
\hline \multicolumn{8}{|l|}{$\begin{array}{l}\text { Valores calculados } \\
\text { Calculated values }\end{array}$} \\
\hline $\mathrm{ED}, \mathrm{kcal} / \mathrm{kg}$ (Digestible energy, $\mathrm{kcal} / \mathrm{kg}$ ) & 3.400 & 3.400 & 3.400 & 3.400 & 3.400 & 3.400 & 3.400 \\
\hline Lisina total, \% (Total lysine, \%) & 1,060 & 1,060 & 1,060 & 1,060 & 1,060 & 1,060 & 1,060 \\
\hline Met + Cis total, \% (Total Met + Cys, \%) & 0,630 & 0,630 & 0,630 & 0,630 & 0,630 & 0,630 & 0,630 \\
\hline Cálcio, \% (Calcium, \%) & 0,830 & 0,830 & 0,830 & 0,830 & 0,830 & 0,830 & 0,830 \\
\hline $\mathrm{P}$ disponível, \% (Available phosphorus, \%) & 0,430 & 0,430 & 0,430 & 0,430 & 0,430 & 0,430 & 0,430 \\
\hline Proteína bruta, \% (Crude protein, \%) & 19,000 & 18,694 & 18,383 & 18,072 & 19,206 & 19,411 & 19,613 \\
\hline Custo da ração, $\mathrm{R} \$ / \mathrm{kg}$ (Diet cost, $R \$ / \mathrm{kg}$ ) & 0,476 & 0,466 & 0,456 & 0,445 & 0,459 & 0,443 & 0,426 \\
\hline
\end{tabular}

As rações foram pesadas diariamente e fornecidas na forma farelada. Tanto a água como os alimentos foram fornecidos à vontade. Todas as sobras das rações foram pesadas e descartadas 24 horas após o fornecimento.

Os valores de $\mathrm{pH}$ das silagens foram obtidos seguindo os procedimentos utilizados por Phillip \& Fellner (1992). As análises de granulometria das silagens foram realizadas de acordo com a metodologia proposta por Zanotto \& Bellaver(1996).

Os preços dos ingredientes utilizados na composição das dietas experimentais foram: milho grão, $\mathrm{R} \$ 0,255 / \mathrm{kg}$; farelo de soja, R\$ 0,62/kg; óleo de soja R \$1,88/kg; açúcar cristal R \$ 0,54/kg; fosfato bicálcico, R \$0,82/kg; calcário, $\mathrm{R} \$ 0,13 / \mathrm{kg}$; sal comum, R \$ 0,20/kg; L-lisina HCl, R \$ 10,00/kg; DL-metionina, R\$12,50/kg, Tylan S-100, R\$ 31,00/kg; e suplemento vitamínico e mineral, R $\$ 7,96 / \mathrm{kg}$. O preço da SGUS foi de R $\$ 0,18 / \mathrm{kg}$, quando ajustado para a mesma base de MS do milho seco (87,45\%). Essa estimativa foi feita de acordo com o custo de produção, considerando os custos de plantio, colheita, transporte e ensilagem (trituração e compactação) das SGUS, com produtividade média de $5.500 \mathrm{~kg} / \mathrm{ha}$ (produtividade média da região).

Para verificar a viabilidade econômica da substituição do milho seco pelas SGUS nas rações, foi determinado inicialmente o custo de ração por quilograma de peso vivo ganho (Yi), segundo Bellaver et al. (1985). Em seguida, foram calculados o índice de eficiência econômica (IEE) e o índice de custo (IC), proposto por Gomes et al. (1991).

O consumo diário de ração (CDR), o ganho diário de peso (GDP), a conversão alimentar (CA) e as variáveis econômicas foram analisados utilizando-se o seguinte modelo estatístico:

$$
\mathrm{Y}_{i j k l}=\mu+\mathrm{F}_{i}+\mathrm{N}_{j}+\mathrm{FN}_{i j}+\mathrm{S}_{\mathrm{k}}+\mathrm{b}_{1}\left(\mathrm{Pi}_{i j k}-\mathrm{Pi}\right)+\mathrm{e}_{i j k l}
$$
em que: $\mathrm{Y}_{i j k l}=$ observação $l$ do sexo $k$, do nível de substituição $j$, referente ao efeito da variedade do sorgo $i$; $\mu=$ constante geral; $\mathrm{F}_{i}=$ efeito da variedade de sorgo $i$, com $i=1 ; 2$ ( $1=$ silagem de grãos úmidos de sorgo de alto teor de tanino e 2 = silagem de grãos úmidos de sorgo de baixo teor de tanino); $\mathrm{N}_{j}=$ efeito do nível de substituição $j$; $\mathrm{FN}_{i j}=$ efeito da interação do efeito da variedade de sorgo 
Tabela 2 - Composições química e energética dos ingredientes das rações experimentais (na matéria natural) Table 2 - Chemical and energy compositions of ingredients of the experimental diets (as-fed basis)

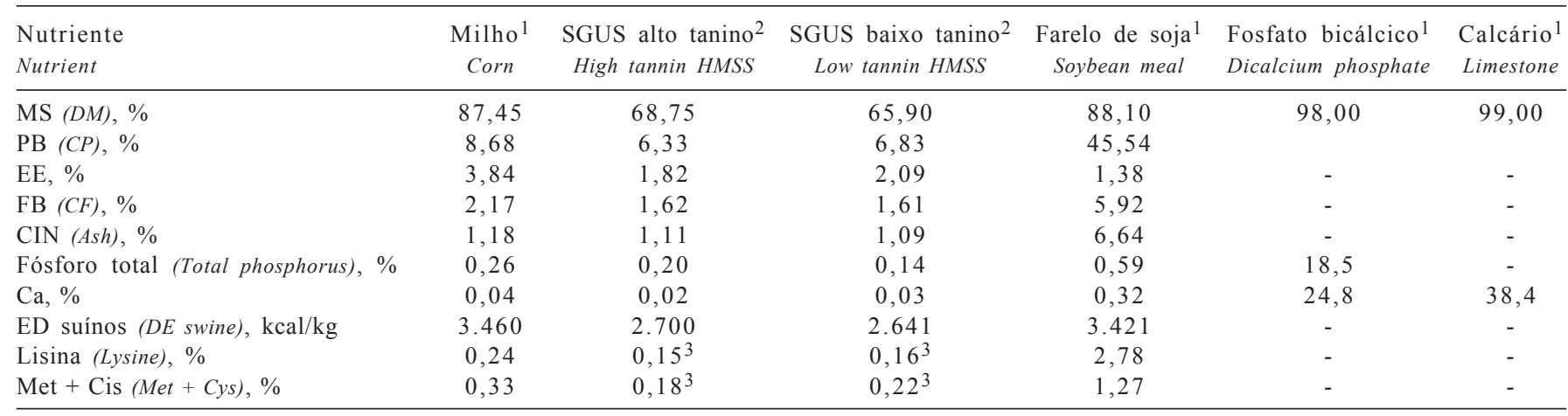

1 Dados baseados nas tabelas da EMBRAPA (1991).

2 Resultados de análises realizadas no Laboratório de Alimentação e Nutrição Animal do Departamento de Zootecnia da UEM (LANA-DZO/UEM).

3 Calculado de acordo com o teor de PB (6,33\% para SGUS de alto teor de tanino e $6,83 \%$ para SGUS de baixo teor de tanino), determinado no LANA-DZO/ UEM, e com as concentrações de aminoácidos apresentadas nas tabelas da EMBRAPA (1991).

1 Data from EMBRAPA (1991) tables.

2 Results of analysis done at the Feed and Animal Nutrition Laboratory of Animal Science Department of UEM (LANA-DZO/UEM).

${ }^{3}$ Calculated according to the crude protein content (6.33\% of high tannin HMSS and $6.83 \%$ of low tannin HMSS) determined at LANA-DZO/UEM and to the concentrations of amino acids from EMBRAPA (1991) tables.

$i$ com o nível de substituição $j$; $\mathrm{S}_{k}=$ efeito do sexo $k$, com $k=1,2 ; \mathrm{b}_{1}=$ coeficiente de regressão linear da variável $\mathrm{Y}$ em função do peso inicial (Pi) e; $\mathrm{e}_{i j k}=$ erro aleatório associado à cada observação $\mathrm{Y}_{i j k}$. Quando houve interação significativa da variedade de sorgo com o nível de substituição, procedeu-se ao desdobramento da interação aninhando nível dentro de cada variedade de sorgo.

Os graus de liberdade referentes aos níveis de substituição do milho seco pela SGUS de alto ou baixo teor de tanino foram desdobrados em polinômios ortogonais.

Para comparação da ração-referência com cada um dos níveis de substituição do milho por SGUS de alto ou de baixo teor de tanino, utilizou-se o teste de Dunnett $(\mathrm{P}<0,05)$.

Na Tabela 2, estão apresentados a composição química e os valores energéticos dos ingredientes utilizados na formulação das dietas experimentais.

\section{Resultados e Discussão}

Na Tabela 3 constam a composição química, o teor de energia bruta, o valor do $\mathrm{pH}$ e o diâmetro geométrico médio das partículas das SGUS de alto e baixo conteúdo de tanino.

A SGUS de baixo teor de tanino apresentou valores nutricionais numericamente superiores, com exceção do fósforo total e do amido, aos da SGUS de alto teor de tanino, quando comparados na mesma base de MS (Tabela 3). Essas variações nos teores de nutrientes entre as silagens podem ser atribuídas a fatores como: potencial genético das sementes para esse atributo, nível de adubação utilizado (especialmente N), fertilidade do solo e condições climáticas (Lima et al., 1998).
Os valores de $\mathrm{pH}$ das silagens de sorgo de 4,55 para a SGUS de alto teor de tanino e 4,32 para a de baixo conteúdo de tanino podem ser considerados satisfatórios, pois foram próximos ao citado por Romero et al. (1996), de 4,2 para silagens de grãos úmidos de sorgo.

Os diâmetros geométricos médios das partículas das SGUS de 571 e $678 \mathrm{~mm}$ para as SGUS de alto e baixo teor de tanino estão de acordo com o recomendado por Healy et al. (1994), de 500 a $800 \mathrm{~mm}$ e pode ser aumentado de acordo com a idade dos suínos.

Os teores de tanino no sorgo de baixo conteúdo de tanino variaram de 0,44 a $0,69 \%$ (Tabela 4 ). De acordo com Magalhães et al. (2000), percentuais abaixo de 0,70\% de polifenóis totais são decorrentes de outros fenóis e não prejudicam o desempenho animal. Zardo \& Lima (1999), no entanto, afirmam que o sorgo com $0,60 \%$ de tanino, analisado pelo Método Azul da Prússia, é considerado sem tanino.

Os teores de tanino para o sorgo com alto conteúdo de tanino variaram de $1,44 \%$ nos grãos secos antes do plantio e 1,14\% nas SGUS após o período fermentativo, confirmando que, durante o processo fermentativo, houve redução de $20 \%$ do teor de tanino nos grãos. Entretanto, o processo de ensilagem não foi eficiente em remover grande parte do tanino presente. De acordo com Mitaru et al. (1984b), no processo de reconstituição, que envolve a adição de água e a subseqüente incubação anaeróbica a $25^{\circ} \mathrm{C}$, ocorre remoção de até $97 \%$ do tanino quimicamente detectável.

Embora não se tenha obtido diferenças $(\mathrm{P}>0,05)$ entre os coeficientes de digestibilidade da MS, PB, MO, EB e CMEB para as silagens de grãos úmidos de sorgo (Tabela 5), a SGUS de baixo conteúdo de tanino apresentou superioridade 
Tabela 3 - Teores de MS, PB, EE, FB, cinzas, cálcio, fósforo total, EB, valor de pH e diâmetro geométrico médio das partículas das silagens de grãos úmidos de sorgo (SGUS) ${ }^{1}$ de alto e baixo conteúdo de taninos, na matéria natural e em $87,45 \%$ de matéria seca

Table 3 - Contents of DM, CP, EE, CF, ash, calcium, total phosphorus, GE, pH value and medium geometric diameter of particles of high moisture sorghum silage (HMSS) ${ }^{1}$ of high or low tannin contents, as-fed basis and on $87.45 \%$ of dry matter basis

\begin{tabular}{|c|c|c|c|c|}
\hline \multirow[t]{2}{*}{$\begin{array}{l}\text { Parâmetro } \\
\text { Parameter }\end{array}$} & \multicolumn{2}{|c|}{$\begin{array}{c}\text { SGUS }^{2} \\
H M S S\end{array}$} & \multicolumn{2}{|c|}{$\begin{array}{l}\text { SGUS }^{3} \\
\text { HMSS }\end{array}$} \\
\hline & $\begin{array}{l}\text { Alto tanino } \\
\text { High tannin }\end{array}$ & $\begin{array}{l}\text { Baixo tanino } \\
\text { Low tannin }\end{array}$ & $\begin{array}{l}\text { Alto tanino } \\
\text { High tannin }\end{array}$ & $\begin{array}{l}\text { Baixo tanino } \\
\text { Low tannin }\end{array}$ \\
\hline $\operatorname{MS}(D M), \%$ & 68,75 & 65,90 & 87,45 & 87,45 \\
\hline $\mathrm{PB}(C P), \%$ & 6,33 & 6,83 & 8,05 & 9,07 \\
\hline Amido (Starch), \% & 45,21 & 43,00 & 57,51 & 57,06 \\
\hline $\mathrm{FB}(C F), \%$ & 1,62 & 1,61 & 2,06 & 2,13 \\
\hline Cinzas $(A s h), \%$ & 1,11 & 1,09 & 1,41 & 1,45 \\
\hline Cálcio (Calcium), \% & 0,02 & 0,03 & 0,02 & 0,04 \\
\hline Fósforo total (Total phosphorus), \% & 0,20 & 0,14 & 0,25 & 0,18 \\
\hline $\mathrm{EB}(G E), \mathrm{kcal} / \mathrm{kg}$ & 2.981 & 2.876 & 3.792 & 3.816 \\
\hline $\mathrm{pH}$ & 4,55 & 4,32 & - & - \\
\hline
\end{tabular}

Tabela 4 - Conteúdos de tanino/compostos fenólicos nos grãos secos, nos grãos úmidos e nas silagens de grãos úmidos de sorgo de alto e baixo conteúdo de tanino

Table 4 - Contents of tannins/phenol compounds in dry grain, high moisture grain and high moisture sorghum silage grain of high and low tannin contents

\begin{tabular}{lcc}
\hline $\begin{array}{l}\text { Parâmetro } \\
\text { Parameter }\end{array}$ & \multicolumn{2}{c}{ SGUS } \\
\cline { 2 - 3 } & $\begin{array}{c}\text { Alto tanino, \% } \\
\text { High tannin, \% }\end{array}$ & $\begin{array}{c}\text { Baixo tanino, \% } \\
\text { Low tannin, \% }\end{array}$ \\
\hline $\begin{array}{l}\text { Grão seco } \\
\text { Dry grain } \\
\text { Grãos úmidos } \\
\begin{array}{l}\text { High moisture grain } \\
\text { Silagem } \\
\text { Silage }\end{array}\end{array}$ & 1,44 & 0,44 \\
\hline
\end{tabular}

numérica em 3,34\% para CDMO, em 1,28\% para CDEB e em 1,01\% para CMEB em relação à SGUS de alto tanino.

Segundo Halley et al. (1986), o CMEB tende a diminuir com o aumento do conteúdo de tanino nas dietas, visto que os taninos podem formar complexos com carboidratos, reduzindo a atividade da enzima amilase e, conseqüentemente, o metabolismo e o aproveitamento energético do carboidrato.

Os coeficientes de digestibilidade da PB das silagens de alto e baixo conteúdo de tanino foram semelhantes, não sendo observada interferência do teor de tanino na dieta para leitões na fase de creche. Rostagno et al. (1983) encontraram valores inferiores de CDPB de grãos de sorgo seco de baixo $(78,6 \%)$ e alto tanino $(62,2 \%)$ para leitões na fase de crescimento.
Tabela 5 - Coeficientes de digestibilidade aparente da MS (CDMS), da PB (CDPB), do amido (CDAM) da MO (CDMO), da EB (CDEB) e coeficiente de metabolização da EB (CMEB) da silagem de grãos úmidos de sorgo (SGUS) de alto ou baixo conteúdo de tanino

Table 5 - Coefficients of apparent digestibility of DM (DMDC), CP $(C P D C)$, starch (SDC), OM (OMDC), GE (GEDC) and coefficient of metabolization of GE (GEMC) of high moisture sorghum silage (HMSS) grain of high or low tannin contents

\begin{tabular}{lccc}
\hline Item & \multicolumn{3}{c}{ SGUS } \\
Item & \multicolumn{3}{c}{ CV (\%) } \\
\cline { 2 - 3 } & $\begin{array}{c}\text { Alto tanino } \\
\text { High tannin }\end{array}$ & $\begin{array}{c}\text { Baixo tanino } \\
\text { Low tannin }\end{array}$ \\
\hline CDMS (DMDC), \% & 92,98 & 93,62 & 4,54 \\
CDPB (CPDC), \% & 86,21 & 86,76 & 8,24 \\
CDAM (SDC), \% & 100,00 & 100,00 & 0,00 \\
CDMO (OMDC), \% & 93,81 & 97,15 & 2,87 \\
CDEB (GEDC), \% & 90,56 & 91,84 & 3,91 \\
CMEB (GEDM), \% & 89,68 & 90,69 & 3,71 \\
\hline
\end{tabular}

Médias, na linha, não diferem $(P>0,05)$ pelo teste $F$. Means in a row do not differ $(P>.05)$ by $F$ test.

A digestibilidade do amido, independentemente da variedade da silagem, foi total, ou seja, o tanino presente nos grãos não reduziu a digestibilidade do amido, fato observado também por Lin et al. (1987) para grãos de sorgo de baixo tanino e por Lizardo et al. (1995) para grãos de sorgo de alto tanino para leitões em fase inicial.

Cousins et al. (1981) afirmam que a digestibilidade do amido do grão de sorgo de baixo conteúdo de tanino é semelhante à do milho em suínos em fase de crescimento.

De acordo com Rooney \& Pflugfelder (1986), o amido do grão de sorgo possui digestão mais lenta que o do milho, 
visto que a camada do endosperma periférico é mais resistente às enzimas digestivas. A digestão do amido dos grãos ensilados com alta umidade, no entanto, é mais rápida, pois ocorre a quebra da estrutura protéica do grão, desfazendo a estrutura cristalina do amido (Ondarza, 2000).

Para comparação dos dados obtidos (Tabela 6) com os de outros autores, os teores de nutrientes digestíveis foram convertidos para $87,45 \%$ de MS, com base na MS do milho seco comum, de acordo com a tabela da EMBRAPA (1991).

Os teores de MSD, PD e AMD das silagens de grãos úmidos de sorgo de alto e de baixo conteúdo de tanino foram semelhantes. As SGUS de alto e de baixo conteúdo de tanino apresentaram 55,90 e 54,04\% de MSD, respectivamente. Valores superiores foram obtidos por Mitaru et al. (1984b), para sorgo reconstituído de alto e baixo conteúdo de tanino (75,69 e 78,50\%, respectivamente), e por Oliveira et al. (2004), para silagem de grãos úmidos de milho (70,76\%) em leitões em fase de creche.

Nunes et al. (2001) afirmam que o tanino condensado, além de afetar o valor nutricional dos alimentos, formando complexos com proteínas, íons metálicos divalentes, carboidratos e outras macromoléculas, também atua inibindo a atividade de várias enzimas digestivas e provocando erosões das células epiteliais do intestino, diminuindo a absorção dos nutrientes através da parede intestinal.

As silagens de grãos úmidos de sorgo de alto e baixo conteúdo de tanino apresentaram 3.434 e $3.505 \mathrm{kcal} / \mathrm{kg}$ de ED e 3.400 e $3.461 \mathrm{kcal} / \mathrm{kg}$ de EM, respectivamente. Resultados semelhantes foram obtidos por Oliveira (2002) em leitões na fase de creche utilizando silagem de grãos úmidos de milho (3.471 de ED e $3.381 \mathrm{kcal} / \mathrm{kg}$ de EM), quando comparadas na mesma base de MS.

Segundo Fialho \& Barbosa (1992), a presença de tanino forma o complexo tanino-carboidrato, reduzindo a atividade da enzima amilase e ocasionando redução no metabolismo de carboidratos e, conseqüentemente, diminuindo o aproveitamento energético do carboidrato. De acordo com Rostagno (1986), o valor de EM está inversamente relacionado ao conteúdo de tanino do cereal, sendo impossível citar somente um valor energético para todas as variedades de sorgo.

Como descrito na Tabela 7, a temperatura da silagem de sorgo de baixo conteúdo de tanino aumentou até 3 horas após a abertura do silo, indicando atividade microbiológica neste período. Kung Jr. (2001) define a estabilidade aeróbia da silagem como o tempo para que a massa de forragem retirada do silo apresente elevação de $2^{\circ} \mathrm{C}$ em relação à temperatura ambiente. Assim, silagens estáveis apresentam baixa velocidade de deterioração na superfície frontal (painel), enquanto as de baixa estabilidade apresentam rápida deterioração. Portanto, a estabilidade aeróbica pode ser definida como a velocidade de deterioração da forragem ensilada após a abertura do silo, devendo-se salientar que silagens ricas em nutrientes ou de boa qualidade apresentam substrato que propicia boas condições para o desenvolvimento de microrganismos.

Segundo Cai et al. (1999), silagens bem preservadas são freqüentemente consideradas mais propensas à deterioração aeróbia que aquelas mal fermentadas. A deterioração aeróbia resulta em perdas de MS e de importantes componentes nutricionais pela oxidação do ácido lático e de carboidratos solúveis. O acúmulo de produtos da degradação pode afetar a palatabilidade e, consqüentemente, reduzir a ingestão (Holzer et al., 1999).

A estabilidade aeróbica da SGUS de alto conteúdo de tanino foi considerada satisfatória, visto que esta silagem não apresentou alterações importantes na temperatura até 6 horas após a abertura do silo.

Tabela 6 - Teores de MS (MSD), proteína (PD), amido (AMD), MO (MOD) e energia digestíveis (ED) e energia metabolizável (EM) da SGUS de alto ou baixo teor de tanino, na matéria natural e em $87,45 \%$ de MS

Table 6 - Contents of digestible DM (DDM), digestible protein (DP), digestible starch (DS), digestible OM (OMD), digestible energy (DE) and metabolizable energy (ME) of high moisture sorghum silage (HMSS) ${ }^{1}$, as-fed basis and on $87.45 \%$ of DM

\begin{tabular}{|c|c|c|c|c|}
\hline \multirow[t]{2}{*}{$\begin{array}{l}\text { Nutriente } \\
\text { Nutrient }\end{array}$} & \multicolumn{2}{|c|}{$\begin{array}{c}\text { SGUS }^{1} \\
\text { HMSS }\end{array}$} & \multicolumn{2}{|c|}{$\begin{array}{c}\text { SGUS }^{2} \\
\text { HMSS }\end{array}$} \\
\hline & $\begin{array}{l}\text { Alto tanino } \\
\text { High tannin }\end{array}$ & $\begin{array}{l}\text { Baixo tanino } \\
\text { Low tannin }\end{array}$ & $\begin{array}{l}\text { Alto tanino } \\
\text { High tannin }\end{array}$ & $\begin{array}{l}\text { Baixo tanino } \\
\text { Low tannin }\end{array}$ \\
\hline $\operatorname{MSD}(D D M), \%$ & 43,94 & 40,72 & 55,90 & 54,04 \\
\hline $\mathrm{PD}(D P), \%$ & 5,45 & 5,92 & 6,94 & 7,86 \\
\hline AMD (DS), \% & 46,67 & 44,08 & 59,36 & 58,49 \\
\hline MOD (OMD), \% & 63,46 & 63,75 & 80,72 & 84,60 \\
\hline $\mathrm{ED}(D E), \mathrm{kcal} / \mathrm{kg}$ & 2.700 & 2.641 & 3.434 & 3.505 \\
\hline $\mathrm{EM}(M E), \mathrm{kcal} / \mathrm{kg}$ & 2.674 & 2.608 & 3.400 & 3.461 \\
\hline
\end{tabular}

\footnotetext{
1 Valores na matéria natural.

2 Valores convertidos para $87,45 \%$ de matéria seca (MS) conforme os dados apresentados na tabela da EMBRAPA (1991) para o milho seco (grão).

${ }^{1}$ As-fed basis values.

2 Values converted for $87.45 \%$ of dry matter (DM) basis according to data from EMBRAPA (1991) tables for dry yellow corn (grain).
} 
A baixa estabilidade para a SGUS de baixo conteúdo de tanino pode estar relacionada ao tipo de silo utilizado, pois, para essa silagem, foram utilizadas manilhas de concreto com capacidade para $1.000 \mathrm{~L}$, enquanto, para a SGUS de alto conteúdo de tanino, foram utilizados tambores de polietileno de 200 L, que permitiram melhor vedação do material ensilado, garantindo melhor qualidade de fermentação e menor área de superfície em contato com o ambiente.

À exceção da ração testemunha, a análise de regressão comprovou aumento linear do $\operatorname{CDR}(\mathrm{P}<0,05)$ com o aumento dos níveis de substituição da SGUS de baixo conteúdo de tanino (Tabela 8). Esse aumento pode ser atribuído à melhora na palatabilidade da ração à medida que o milho foi substituído pela SGUS de baixo conteúdo de tanino.

Para a silagem de alto conteúdo de tanino, o CDR e as demais características de desempenho foram semelhantes $(\mathrm{P}>0,05)$. Lopes et al. (2002) também não notaram efeito dos tratamentos sobre o CDR com SGUS de alto conteúdo de tanino quando comparada ao milho e ao sorgo seco.

Queiroz et al. (1977), contudo, evidenciaram tendências no aumento do consumo, e piora na conversão alimentar à medida que elevaram o nível de substituição do milho pelo sorgo seco de alto conteúdo de tanino.

Neste experimento, a ausência de efeitos negativos do tanino no desempenho dos leitões pode estar relacionada à redução de aproximadamente $20 \%$ do tanino presente na SGUS durante o processo de ensilagem, o que pode ter sido suficiente para amenizar os efeitos prejudiciais do tanino nos leitões na fase de creche.

Os resultados da análise econômica, considerando o custo da SGUS de alto ou baixo teor de tanino (R\$10,80 a saca de $60 \mathrm{~kg}$ ensilada) e o preço do milho comum ( $\mathrm{R} \$ 15,30$ a saca), ajustados para a mesma base de $\operatorname{MS}(87,45 \%)$, encontram-se na Tabela 9.

Tabela 7 - Estabilidade aeróbia das silagens de grãos úmidos de sorgo de alto e baixo conteúdo de tanino, medidas por meio do controle de temperatura

Table 7 - Aerobic stability of high moisture sorghum silage of high or low tannin contents measured by the temperature control

\begin{tabular}{|c|c|c|c|c|}
\hline \multicolumn{3}{|c|}{$\begin{array}{l}\text { Horas após abertura dos silos } \\
\text { Time after silo opening }\end{array}$} & \multicolumn{2}{|c|}{$\begin{array}{l}\text { SGUS de baixo tanino } \\
\text { HMSS of low tannin }\end{array}$} \\
\hline & $\begin{array}{l}\text { Temperatura ambiente, },{ }^{\circ} \mathrm{C} \\
\text { Environment temperature, }{ }^{\circ} \mathrm{C}\end{array}$ & $\begin{array}{c}\text { Temperatura da silagem, }{ }^{\circ} \mathrm{C} \\
\text { Silage temperature, }{ }^{\circ} \mathrm{C}\end{array}$ & $\begin{array}{l}\text { Temperatura ambiente, }{ }^{\circ} \mathrm{C} \\
\text { Environment temperature, }{ }^{\circ} \mathrm{C}\end{array}$ & $\begin{array}{c}\text { Temperatura da silagem, }{ }^{\circ} \mathrm{C} \\
\text { Silage temperature, }{ }^{\circ} \mathrm{C}\end{array}$ \\
\hline 0 & 19,5 & 21,4 & 13,0 & 17,0 \\
\hline 1 & 19,4 & 19,8 & 12,9 & 17,2 \\
\hline 2 & 19,0 & 19,7 & 14,0 & 18,5 \\
\hline 3 & 19,0 & 19,2 & 16,1 & 19,5 \\
\hline 6 & 20,5 & 19,7 & 20,0 & 19,8 \\
\hline 7 & 23,2 & 20,5 & 23,8 & 19,6 \\
\hline 8 & 23,5 & 21,2 & 22,6 & 19,2 \\
\hline 9 & 23,2 & 21,4 & 21,9 & 20,0 \\
\hline 10 & 23,0 & 21,3 & 21,8 & 20,7 \\
\hline
\end{tabular}

Tabela 8 - Consumo diário de ração (CDR), ganho diário de peso (GDP) e conversão alimentar (CA) de suínos em fase de creche alimentados com rações contendo níveis crescentes de substituição do milho seco por SGUS de alto ou baixo conteúdo de tanino no período de 21 dias

Table 8 - Daily feed intake (DFI), daily weight gain (DWG) and feed:gain ratio (F:G) of piglets fed diets with increasing dry corn replacement with HMSS levels in 21-d period

\begin{tabular}{|c|c|c|c|c|c|c|c|c|c|c|}
\hline \multirow[t]{3}{*}{$\begin{array}{l}\text { Item } \\
\text { Item }\end{array}$} & \multicolumn{8}{|c|}{$\begin{array}{l}\text { Nível de substituição do milho seco por SGUS (\%) } \\
\text { Level of dry corn replacement with HMSS (\%) }\end{array}$} & \multirow{3}{*}{$\begin{array}{l}\text { Média } \\
\text { Mean }\end{array}$} & \multirow[t]{3}{*}{$\mathrm{CV}, \%$} \\
\hline & \multirow[b]{2}{*}{0} & \multicolumn{3}{|c|}{$\begin{array}{l}\text { Alto tanino } \\
\text { High tannin }\end{array}$} & \multirow[t]{2}{*}{$\begin{array}{l}\text { Média } \\
\text { Mean }\end{array}$} & \multicolumn{3}{|c|}{$\begin{array}{l}\text { Baixo tanino } \\
\text { Low tannin }\end{array}$} & & \\
\hline & & 33 & 66 & 100 & & 33 & 66 & 100 & & \\
\hline $\begin{array}{l}\text { CDR, } \mathrm{kg} / \mathrm{dia}^{1} \\
D F I, \mathrm{~kg} / \text { day }\end{array}$ & 1,360 & 1,328 & 1,394 & 1,336 & 1,353 & 1,381 & 1,397 & 1,545 & 1,433 & 7,24 \\
\hline $\begin{array}{l}\text { CA } \\
F: G\end{array}$ & 1,998 & 1,982 & 2,022 & 1,916 & 1,968 & 1,924 & 2,017 & 1,980 & 1,979 & 4,70 \\
\hline
\end{tabular}

${ }^{1}$ Efeito linear $(P<0,05)$ dos níveis de substituição por SGUS de baixo tanino $(\hat{Y}=1,225333+0,002458 X)$.

${ }^{1}$ Linear effect $(P<0.05)$ of replacement levels for HMSS of low tannin $(\hat{Y}=1.225333+0.002458 X)$. 
Tabela 9 - Custo do quilograma de ração, custo de ração por quilograma de peso vivo ganho (CR) dos leitões, índice de eficiência econômica (IEE) e índice de custo (IC)

Table 9 - Diet cost per kilogram, diet cost per kilogram of piglets body weight (DC), economic efficiency index (EER) and cost index (CR)

\begin{tabular}{|c|c|c|c|c|c|c|c|c|}
\hline \multirow[t]{3}{*}{$\begin{array}{l}\text { Item } \\
\text { Item }\end{array}$} & \multirow[t]{3}{*}{$\begin{array}{c}\text { Ração-referência } \\
\text { Control }\end{array}$} & \multicolumn{6}{|c|}{$\begin{array}{l}\text { Nível de substituição do milho seco por SGUS (\%) } \\
\text { Level of dry corn replacement with HMSS (\%) }\end{array}$} & \multirow{3}{*}{$\mathrm{CV}, \%$} \\
\hline & & \multicolumn{3}{|c|}{$\begin{array}{l}\text { Alto tanino } \\
\text { High tannin }\end{array}$} & \multicolumn{3}{|c|}{$\begin{array}{l}\text { Baixo tanino } \\
\text { Low tannin }\end{array}$} & \\
\hline & & 33 & 66 & 100 & 33 & 66 & 100 & \\
\hline $\begin{array}{l}\text { Custo da ração }{ }^{1}, \mathrm{R} \$ / \mathrm{kg} \\
\text { Diet cost, } R \$ / \mathrm{kg}\end{array}$ & 0,476 & 0,466 & 0,456 & 0,445 & 0,460 & 0,443 & 0,426 & - \\
\hline $\begin{array}{l}\text { IEE } \\
\text { EER }\end{array}$ & 90 & 89 & 93 & 100 & 97 & 96 & 97 & - \\
\hline $\begin{array}{l}\mathrm{IC} \\
C R\end{array}$ & 111 & 112 & 107 & 100 & 103 & 104 & 103 & - \\
\hline
\end{tabular}

${ }^{1}$ Custos baseados em uma relação de preços para a SGUS de $70,59 \%$ do valor (R\$) do milho seco comum.

${ }^{2}$ Custo em ração por kg de PV ganho no período, efeito linear $(P<0,05), \hat{Y}=1,0126960-0,00160081 X$ para os níveis de substituição da SGUS de alto conteúdo de taninos

1 Costs based on prices relationship for HMSS of $70.59 \%$ (R\$) of dry corn value.

2 Diet cost per $k g$ of $B W$ gain in period, linear effect $(P<0.05), \hat{Y}=1.0126960-0.00160081 X$ for the dry corn replacement levels with HMSS of high tannin).

O custo da ração por quilograma de peso vivo ganho (CR) dos leitões alimentados com SGUS de alto conteúdo de tanino reduziu linearmente $(\mathrm{P}<0,05)(\hat{\mathrm{Y}}=1,0126960-$ 0,00160081X) com o aumento dos níveis de substituição do milho pela SGUS. Para a SGUS de baixo conteúdo de tanino, não foram observadas diferenças $(\mathrm{P}>0,05)$ entre os diferentes níveis de inclusão.

O melhor IEE e IC foram obtidos quando a SGUS de alto conteúdo de tanino substituiu em $100 \%$ o milho comum das rações.

A redução nos custos por quilograma de leitão produzido foi observada por Ribeiro et al. (2002), ao utilizarem o sorgo seco de baixo conteúdo de tanino em substituição parcial ao milho em dietas para leitões nas fases pré-inicial e inicial.

Portanto, considerando os bons resultados de desempenho e as vantagens do grão de sorgo em comparação ao milho, a SGUS de alto ou baixo teor de tanino pode ser considerada uma opção mais barata em relação ao milho comum, podendo substituir totalmente o milho seco das rações para leitões em fase de creche.

\section{Conclusões}

As silagens de grãos úmidos de sorgo de alto e de baixo conteúdo de tanino possuem bom valor nutritivo e ótimo conteúdo de energia digestível $(2.700$ e $2.641 \mathrm{kcal} / \mathrm{kg}$ na matéria natural, respectivamente) e, portanto, podem substituir totalmente o milho nas rações para leitões em fase de creche, pois não prejudicam o desempenho e apresentam menores custos por quilograma de leitão produzido.

\section{Literatura Citada}

BELLAVER, C.; FIALHO, E.T.; PROTAS, J.F.S. et al. Radícula de malte na alimentação de suínos em crescimento e terminação. Pesquisa Agropecuária Brasileira, v.20, n.8, p.969-974, 1985.

CAI, Y.; BENNO, Y.; OGAWA, M. et al. Effect of applying lactic acid bacterial isolated from forage crops on fermentation characteristics and aerobic deterioration of silage. Journal of Dairy Science, v.82, n.7, p.520-526, 1999.

CRENSHAW, J.D.; PEO JR., E.R.; LEWIS, A.J. et al. The effects of sorbic acid in high moisture sorghum grain diets on performance of weanling swine. Journal of Animal Science, v.63, n.3, p.831-837, 1986.

COUSINS, B.W.; TANKSLEY, T.D.; KNABE, D.A. et al. Nutrient digestibility and performance of pigs fed sorghums varying in tannin concentration. Journal of Animal Science, v.53, n.6, p.1524-1537, 1981.

EMPRESA BRASILEIRA DE PESQUISA E AGROPECUÁRIA EMBRAPA. Centro Nacional de Pesquisa de Suínos e Aves CNPSA. Tabela de composição química e valores energéticos de alimentos para suínos e aves. 3.ed. Concórdia: 1991. 97p.

FIALHO, E.T.; BARBOSA, H.C. Utilização de sorgo em rações para suínos e aves. Sete Lagoas: EMBRAPA - CNPMS, 1992. 19p (Circular Técnica, 16).

GOMES, M.F.M.; BARbosA, H.P.; FiALhO, E.T. et al. Análise econômica da utilização do triguilho para suínos. ( $S . I$ ): EMBRAPA - Centro Nacional de Pesquisa de Suínos e Aves, 1991, p.1-2 (Comunicado Técnico, 179).

GONTIJO, V.P.M.; PEREIRA, J.A.A.; COSTA, P.M.A. et al. Substituição do milho pelo sorgo e sua suplementação com lisina e metionina em rações para suínos. Revista da Sociedade Brasileira de Zootecnia, v.5, n.1, p.83-95, 1976.

HALLEY, J.T.; NELSON, T.S.; KIRB, L.K. et al. The effect of tannin content of sorghum grain in poultry rations on dry matter digestion and energy utilization. Arkansas Farm Research, v.35, n.2, p.8, 1986.

HEALY, B.J.; HANCOCK, J.D.; KENNEDY, G.A. et al. Optimum particle size of corn and hard and soft sorghum for nursery pigs. Journal of Animal Science, v.72, n.9, p.2227-2236, 1994.

HOLZER, M.; MAYRHUBER, H.; DANNER, L. Effect of Lactobacillus sp. on silaging and aerobic stability. In: INTERNATIONAL 
SILAGE CONFERENCE, 12., 1999, Uppsala. Anais... Uppsala: Sweden, 1999. p.288-289.

KRAMER, J.; VOORSLUYS, J.L. Silagem de milho úmido, uma boa opção para gado leiteiro. In: SIMPÓSIO SOBRE NUTRIÇÃO DE BOVINOS, 4., 1991, Piracicaba. Anais... Piracicaba: Fundação de Estudos Agrários Luiz de Queiroz, 1991. p.257-261.

KUNG JR., L. Aditivos microbianos e químicos para silagem - Efeitos na fermentação e resposta animal. In: WORKSHOP SOBRE MILHO PARA SILAGEM, 2., 2001, Piracicaba. Anais... Piracicaba: Fundação de Estudos Agrários Luiz de Queiroz, 2001. p.53-74.

LIMA, G.J.M.M.; SOUZA，O.W.; BELLAVER, C. et al. Determinação da composição química e do valor energético de silagem de grãos úmidos de milho para suínos. In: CONGRESSO NACIONAL DE MILHO E SORGO, 22., 1998, Recife. Anais... Recife: Associação Brasileira de Milho e Sorgo, [1998]. 2 par. CD-ROM. Industrialização e Tecnologia de Alimento.

LIN, F.D.; KNABE, D.A.; TANKSLEY JR., T.D. Apparent digestibility of amino acids, gross energy and starch in corn, sorghum, wheat, barley, oat groats and wheat middlings for growing pigs. Journal of Animal Science, v.64, n.7, p.1655-1663, 1987.

LIZARDO, R.; PEINIAU, J.; AUMAITRE, A. Effect of sorghum tannins on growth, digestibility of diet components and activity of pancreatic and intestinal enzymes in piglets. Journées de la Recherche Porcine en France, v.27, p.209-216, 1995.

LOPES, A.B.R.C.; BERTO, D.A.; COSTA, C. et al. Silagem de grãos úmidos de sorgo com alto e baixo tanino para suínos em fase inicial. In: CONGRESSO LATINO AMERICANO DE SUINOCUltura, 1., 2002, Foz do Iguaçu. Anais... Foz do Iguaçu: 2002. p.243.

MAGALHÃES, P.C.; RODRIGUES, W.A.; DURÃES, F.O.M. Tanino no grão de sorgo: bases fisiológicas e métodos de determinação. Sete Lagoas: EMBRAPA - Centro Nacional de Pesquisa de Milho e Sorgo, 2000. 13p (Circular Técnica, 27).

MAKKAR, H.P.S. Do tannins affect only protein utilization? Indian Daryman, v.41, n.7, p.135-156, 1988

MATTERSON, L.D.; POTTER, L.M.; STUTZ, M.W. et al. The metabolizable energy of feed ingredients for chickens. Research Report, v.7, n.1, p.11-14, 1965.

MENDES, W.S.; FONTES, D.O.; SILVA, I.J. et al. Composição química e digestibilidade aparente do milho e sorgo crus e expandidos para suínos em crescimento. In: CONGRESSO LATINO AMERICANO DE SUINOCULTURA, 1., 2002, Foz do Iguaçu. Anais... Foz do Iguaçu: 2002. p.241.

MITARU, B.N.; REICHERT, R.D.; BLAIR, R. Nutritive value of reconstituted sorghum grains for weanling pigs. Journal of Animal Science, v.58, n.5, p.1211-1215, 1984a.

MITARU, B.N.; REICHERT, R.D.; BLAIR, R. The binding of dietary protein by sorghum tannins in the digestive tract of pigs. The Journal of Nutrition, v.114, n.10, p.1787-1796, 1984b.

MOREIRA, I.; ROSTAGNO, H.S.; COELHO, D.T. et al. Determinação dos coeficientes de digestibilidade, valores energéticos e índices de controle de qualidade do milho e soja integral processados pelo calor. Revista da Sociedade Brasileira de Zootecnia, v.23, p.916-929, 1994.

MYER, R.O.; GORBET, D.W. Waxy and normal grain sorghums with varying tannin contents in diets for young pigs. Animal Feed Science and Technology, v.12, p.179-186, 1985.

NUMMER, I.F. Silagem de grão úmido de milho. In: SIMPÓSIO NACIONAL DE DESENVOLVIMENTO DA SUINOCULTURA, 9., 2001, Gramado. Anais... Gramado, 2001. 22p.

NUNES, R.V.; BUTERI, C.B.; NUNES, C.G.V. et al. Fatores antinutricionais dos ingredientes destinados à alimentação animal. In: SIMPÓSIO SOBRE INGREDIENTES NA ALIMENTAÇÃO ANIMAL, 2001, Campinas. Anais... Campinas, 2001.p.246-272.

OLIVEIRA, R.P.; FURLAN, A.C., MOREIRA, I. et al. Valor nutritivo e desempenho de leitões alimentados com rações contendo silagem de grãos úmidos de milho. Revista Brasileira de Zootecnia, v.33, n.1, p.146-156, 2004.
ONDARZA, B.M. Starch digestibility. [S.I.:Sn]. 2000. Acesso em: 27/07/2000. Disponível em: http://www.farme.com/assets/ articles/STARCHweb.htm

PARR INSTRUMENTS Co., Moline, ie. Instructions for the 1241 and 1242 adiabatic calorimeters. Moline, 1984. 29p (Parr Manual, 153).

PASCULA-REAS, B.A comparative study on the digestibility of cassava, maize, sorghum and barley in various segments of the digestive tract of growing pigs. Livestock Research for Rural Development, v.9, n.5, 10p., 1997.

PEKAS, J.C. Versatile swine laboratory apparatus for physiologic and metabolic studies. Journal of Animal Science, v.27, n.5, p.1303-1309, 1968.

PEREIRA, J.R.A.; ROSSI, J.R.P. Manual prático da avaliação nutricional dos alimentos. Piracicaba: Fundação de Estudos Agrários Luiz de Queiroz, 1995. 25p.

PHILLIP, L.E.; FELLNER, V. Effects of bacterial inoculation of high moisture ear corn on its aerobic stability, digestion and utilization for growth by beef steers. Journal of Animal Science, v.70, p.3178-3187, 1992.

POORE, J.R.; ECK, T.P.; SWINGLE, R.S. et al. Total starch and relative starch availability of grains. In: BIENAL CONFERENCE ON RUMEN FUNCTION, 20., 1989, Chicago. Proceedings... Chicago: 1989. p.35.

QUEIROZ, A.C.; ROSTAGNO, H.S.; COSTA, P.M. et al. Sorgos com diferentes conteúdos de tanino, como substitutos do milho para suínos. Revista da Sociedade Brasileira de Zootecnia, v.6, p.252-261, 1977.

RIBEIRO, R.P.; FEDALTO, L.M.; TKACZ, M. et al. Utilização de sorgo de baixo tanino, com ou sem enzimas, em rações para leitões nas fases pré-inicial e inicial. In: CONGRESSO LATINO AMERICANO DE SUINOCULTURA, 1., 2002, Foz do Iguaçu. Anais... Foz do Iguaçu: 2002. p.243.

ROMERO, L.A.; DIAZ, M.C.; BRUNO, O.A. et al. Silaje de grano húmedo de maiz y sorgo en la alimentación de vacas lecheras. Rafaela: INTA, EEA, 1996. 22p (Informe Técnico, 110).

ROONEY, L.W.; PFLUGFELDER, R.L. Factors affecting starch digestibility with special emphasis on sorghum and corn. Journal of Animal Science, v.63, p.1607-1623, 1986.

ROSTAGNO, H.S. Utilização do sorgo nas rações de aves e suínos. Informe Agropecuário, v.12, n.144, p.18-27, 1986.

ROSTAGNO, H.S.; SILVA, D.J.; COSTA, P.M.A. Composição de alimentos e exigências nutricionais de aves e suínos (tabelas brasileiras). Viçosa, MG: Universidade Federal de Viçosa, 1983. $61 \mathrm{p}$.

ROSTAGnO, H.S.; ALBINO, L.F.T.; DONZELE, J.L. et al. Tabelas brasileiras para aves e suínos: composição de alimentos e exigências nutricionais. 1.ed. Viçosa, MG: Universidade Federal de Viçosa, 2000. 141p.

SILVA, D.J. Análise de alimentos (Métodos químicos e biológicos). 2.ed. Viçosa, MG: Universidade Federal de Viçosa, 1990. 165p.

TEETER, R.G.; SARANI, S.; SMITH, M.O. et al. Detoxification of high tannin sorghum grains. Poultry Science, v.65, n.1, p.67$71,1986$.

Van SOEST, P.J. Nutritional ecology of the ruminant. 2.ed. Cornell University Press, 1994. 476p.

VILJOEN, J. Sorghum as an animal feed. [S.I.:Sn]. 2000 Disponível em: 27/06/2000. Acesso: http://www.agri24.com/ AFMA_Template.

ZANOTTO, L.D.; BELLAVER, C. Método de determinação da granulometria de ingredientes para o uso em rações de suínos e aves. (S.I): EMBRAPA - Centro Nacional de Pesquisa de Suínos e Aves, 1996. p.15 (Comunicado técnico, 215).

ZARDO, A.O.; LIMA, G.J.M.M. Alimentos para suínos EMBRAPA - Centro Nacional de Pesquisa de Suínos e Aves/ EMATER-RS, 1999. 80p (Boletim Informativo).

Recebido: $10 / 11 / 03$ Aprovado: 28/03/06 